\title{
SINTESIS DAN UJI TOKSISITAS SENYAWA ANALOG KALKON DARI 4'- HIDROKSIASETOFENON DENGAN 2-METOKSIBENZALDEHID
}

\author{
Denaria Oktavia $^{1}$, Nur Balatif ${ }^{2}$, Adel Zamri² \\ 1. Mahasiswa Program S1 Kimia FMIPA-Universitas Riau \\ 2. Dosen Jurusan Kimia FMIPA-Universitas Riau \\ Fakultas Matematika dan Ilmu Pengetahuan Alam Universitas Riau \\ Email: adel.zamri@lecturer.unri.ac.id
}

\begin{abstract}
ABSTRAK
Senyawa kalkon (E)-1-(4'- hidroksifenil)-3-(2-metoksifenil)prop-2-en-1-on (DO) telah disintesis melalui kondensasi Clasein-Schmidt antara 4'-hidroksiasetofenon dengan 2-metokibenzaldehid menggunakan katalis basa (KOH) dibawah iradiasi gelombang mikro. Struktur senyawa dikarakterisasi berdasarkan interpretasi data spektroskopi UV, FTIR, ${ }^{1} \mathrm{H}-\mathrm{NMR}$ dan MS. Uji toksisitas senyawa kalkon ditentukan dengan metoda Brine Shrimp Lethality Test terhadap larva Artemia salina Leach dan menunjukkan aktivitas dengan nilai $\mathrm{LC}_{50}$ yaitu 49,54 $\mu \mathrm{g} / \mathrm{mL}$. Hasil tersebut menunjukkan bahwa senyawa DO memiliki aktivitas toksisitas yang cukup baik karena memiliki nilai $\mathrm{LC}_{50}<200$ $\mu \mathrm{g} / \mathrm{mL}$.
\end{abstract}

Kata kunci: kalkon, gelombang mikro, BSLT

\section{PENDAHULUAN}

Kalkon atau 1,3-difenil-2-propen-1-on merupakan rantai terbuka flavonoid yang kedua cincin aromatiknya dihubungkan oleh tiga atom karbon sistem karbonil $\alpha, \beta$ tak jenuh (Patil et al., 2009). Adanya sistem karbonil $\alpha, \beta$ tak jenuh menyebabkan kalkon memiliki banyak aktivitas biologis, beberapa diantaranya adalah antikanker (Syam et al., 2012), analgesik, antijamur, sitotoksik, insektisidal (Ahmed et al., 2011), anti-inflamasi, antioksidan (Chen et al., 2013), antimalarial dan antimikroba (Kamble et al., 2011), larvisidal serta inhibitor beberapa enzim terutama alfa-amilase pada mamalia, siklooksigenase dan monoamin oksidase (Rahman, 2011).

Senyawa kalkon terdistribusi dalam buahbuahan, sayur-sayuran, rempah-rempah, teh dan kedelai. Kalkon di alam jumlahnya relatif sedikit dan variasi strukturnya terbatas. Selain itu, isolasi senyawa kalkon dari alam membutuhkan waktu yang lama dan pengerjaannya cukup rumit. Sintesis merupakan solusi yang tepat untuk mengatasi permasalahan tersebut. Senyawa kalkon dapat disintesis melalui kondensasi aldol dari suatu keton aromatik dan aldehid aromatik baik dalam kondisi asam maupun basa. Beberapa kalkon sudah pernah disintesis menggunakan metode konvensional yaitu gerus dan pengadukan, namun karena membutuhkan waktu yang lama, diperlukan alternatif lain agar proses sintesis berlangsung lebih cepat dan senyawa kalkon yang dihasilkan maksimal. Metode iradiasi gelombang mikro merupakan metode non-konvensional yang diyakini dapat menjadi alternatif pengganti metode konvensional tersebut, dikarenakan waktu reaksi yang lebih cepat dan hasil yang lebih baik dibandingkan dengan metode-metode lainnya (Revathi et al., 2013).

Berdasarkan penelitian yang dilakukan Desmiarti (2012), senyawa dengan substituen metoksi baik pada cincin A maupun B memiliki aktivitas toksisitas yang baik. Ritriani (2011), Hastiningrum (2013) dan Prayitno (2015) juga melakukan penelitian terhadap senyawa kalkon yang mengandung gugus metoksi. Menurut Ritriani (2011) kalkon dengan substituen monometoksi memiliki nilai $\mathrm{LC}_{50}$ yang lebih kecil sehingga lebih berpotensi sebagai antikanker, oleh karena itu penulis tertarik melakukan penelitian tentang aktivitas toksisitas senyawa kalkon tersubstitusi monometoksi dengan posisi substituen yang berbeda pada cincin aromatik B.

Senyawa hasil sintesis dikarakterisasi berdasarkan interpretasi data spektroskopi UVVis, FTIR, ${ }^{1} \mathrm{H}$ NMR dan MS, kemudian diuji 
sifat toksiknya dengan metode Brine Shrimp Lethality Test (BSLT). Pada metode Brine Shrimp Lethality Test (BSLT), suatu tanaman atau hasil isolasi dianggap menunjukkan aktivitas sitotoksik yang baik jika mempunyai nilai $\mathrm{LC}_{50}$ kecil dari $1000 \mu \mathrm{g} / \mathrm{mL}$, sedangkan untuk senyawa murni dianggap menunjukkan aktivitas sitotoksik bila mempunyai nilai LC $_{50}$ kecil dari $200 \mu \mathrm{g} / \mathrm{mL}$ (Meyer, 1982).

\section{METODOLOGI PENELITIAN}

\section{Alat dan Bahan}

Alat-alat yang akan digunakan dalam penelitian ini adalah Microwave (Samsung ME 109F $500 \mathrm{MHz}$ ), alat pengukur titik leleh Fisher John (SMP 11-Stuart ${ }^{\circledR}$ ), lampu 254/366 nm (Camag ${ }^{\circledR}$ ), spektrofotometer UV-Vis (Genesys 10S UV-Vis v4.002 2L9N175013), HPLC (Shimadzu LCsolution jenis kolom shim-pack VP-ODS dengan panjang diameter $150 \times$ 4,6 $\mathrm{mm}$ ), spektrofotometer IR (FTIR Shimadzu, IR Prestige-21), spektroskopi ${ }^{1} \mathrm{H}-\mathrm{NMR}$ (Agilent $500 \mathrm{MHz}$ DD2), spektroskopi Massa (water LCT premier XE mode positif), serta alat-alat untuk sintesis dan uji toksisitas yang umum digunakan di laboratorium.

Bahan-bahan yang digunakan yaitu 4'hidroksiasetofenon (Aldrich), 2metoksibenzaldehid (Merck), kalium hidroksida $(\mathrm{KOH}) 6 \mathrm{~N}$ (Merck), asam klorida $(\mathrm{HCl}) 3 \mathrm{~N}$ (Merck), indikator universal, n-heksana (Merck), etil asetat (Merck), methanol (Merck), etanol absolut (Merck), plat KLT $\mathrm{GF}_{254}$, akuades dan larva Artemia salina $\mathrm{L}$.

\section{Sintesis senyawa kalkon}

Sebanyak 5 mmol 4'-hidroksiasetofenon ditempatkan dalam wadah Erlenmeyer $125 \mathrm{~mL}$, kemudian dilarutkan dengan $7,5 \mathrm{~mL}$ etanol absolut dan ditambahkan dengan 12,5 mL larutan $\mathrm{KOH} 6 \mathrm{~N}$. Campuran didiamkan selama 2 menit, lalu ke dalam campuran dimasukkan sebanyak 5 mmol 2-metoksibenzaldehid. Campuran ini di-iradiasi gelombang mikro selama 10 menit dengan daya 180 watt. Reaksi dipantau melalui uji KLT setiap 2 menit. Kemudian campuran didiamkan selama 20 jam untuk menyempurnakan reaksi. Setelah 20 jam, campuran ditambahkan $15 \mathrm{~mL}$ akuades dingin dan $\mathrm{pH}$ campuran dinetralkan dengan $\mathrm{HCl} 3 \mathrm{~N}$. Campuran dibiarkan di dalam lemari pendingin untuk memaksimalkan hasil reaksi (endapan) yang diperoleh. Endapan yang terbentuk kemudian disaring menggunakan corong buchner sambil dicuci dengan akuades dan nheksana dingin, kemudian dikeringkan pada suhu ruang. Rekristalisasi dilakukan dengan menggunakan etanol. Kemurnian senyawa ditentukan dengan KLT, titik leleh dan analisis HPLC.

Uji toksisitas dengan metode brine shrimp lethality test (BSLT)

Sampel sebanyak $20 \mathrm{mg}$ dilarutkan dalam 2 $\mathrm{mL}$ metanol (larutan induk, konsentrasi 10000 $\mu \mathrm{g} / \mathrm{mL}$ ), kemudian dari larutan induk dibuat konsentrasi yang berbeda $1000 \mu \mathrm{g} / \mathrm{mL}, 100$ $\mu \mathrm{g} / \mathrm{mL}$ dan $10 \mu \mathrm{g} / \mathrm{mL}$ dengan cara pengenceran bertingkat. Kemudian disiapkan vial $5 \mathrm{~mL}$ yang sudah dikalibrasi untuk masing-masing konsentrasi. Sampel dipipet kedalam masingmasing vial sebanyak $0,5 \mathrm{~mL}$, lalu pelarut diuapkan hingga mengering. Selanjutnya, kedalam masing-masing vial ditambahkan $50 \mu \mathrm{L}$ DMSO dan $0,5 \mathrm{~mL}$ air laut. Sebanyak 10 ekor larva udang dimasukkan kedalam vial tersebut dan ditambah air laut hingga batas kalibrasi 5 $\mathrm{mL}$. Tingkat toksisitas diukur dengan cara menghitung jumlah larva udang yang mati dalam selang waktu 24 jam. Pengujian dilakukan tiga kali pengulangan dengan perlakuan yang sama untuk masing-masing konsentrasi. Kemudian $\mathrm{LC}_{50}$ dihitung dengan metode kurva menggunakan tabel analisis probit.

\section{HASIL DAN PEMBAHASAN}

Analisis univariat digunakan untuk menggambarkan pemberian ASI ekslusifpada bayi usia 0 - 6 bulan terhadap pengetahuan dan sikap.

\section{Sintesis senyawa kalkon}

Senyawa kalkon disintesis melalui reaksi kondensasi aldol dari senyawa awal 4'hidroksiasetofenon dan 2-metoksibenzaldehid menggunakan iradiasi gelombang mikro dan penambahan katalis KOH. Senyawa kalkon yang diperoleh dimurnikan dengan rekristalisasi. 
Sintesis senyawa DO dapat dilihat pada

\section{Gambar 1.}<smiles>COc1ccccc1/C=C/C(=O)c1ccc(O)cc1</smiles>

Sintesis yang telah dilakukan menghasilkan senyawa kalkon berupa padatan berwarna kuning dengan berat sebesar 1,1704 g dan rendemen yang dihasilkan sebesar $92,07 \%$. Sifat fisika dari senyawa kalkon yang dihasilkan dapat dilihat pada Tabel 1.

Gambar 1. Sintesis Senyawa DO

Tabel 1. Sifat fisika senyawa DO

\begin{tabular}{cccccc}
\hline Senyawa & Rumus molekul & Berat molekul & Warna & Rendemen $(\%)$ & Titik leleh $\left({ }^{\circ} \mathrm{C}\right)$ \\
\hline Kalkon (DO) & $\mathrm{C}_{16} \mathrm{H}_{15} \mathrm{O}_{3}$ & 254,1021 & kuning & 92,07 & $186-187$ \\
\hline
\end{tabular}

Analisis kemurnian senyawa kalkon dilakukan menggunakan uji KLT, titik leleh, dan HPLC. Analisis kemurnian dengan KLT dilakukan menggunakan eluen yang bervariasi dan perbandingan yang berbeda. Senyawa kalkon menunjukkan satu noda pada plat KLT. Noda pada KLT diamati dengan bantuan lampu UV ( $\lambda 254 \mathrm{~nm}$ dan $366 \mathrm{~nm}$ ). Analisis kemurnian dengan titik leleh menunjukkan bahwa senyawa memiliki range titik leleh sebesar $1^{\circ} \mathrm{C}$. Analisis kemurnian senyawa kalkon menggunakan HPLC dilakukan pada panjang gelombang $236 \mathrm{~nm}$ dan $345 \mathrm{~nm}$ menunjukkan satu puncak dominan pada $\mathrm{t}_{\mathrm{R}}=11$ menit. Berdasarkan data analisis kemurnian tersebut menunjukkan bahwa senyawa kalkon yang diperoleh telah murni.

Spektrum UV senyawa kalkon (DO) memperlihatkan adanya serapan maksimum pada $\lambda$ 204; 236 dan $345 \mathrm{~nm}$ (Gambar 2). Berdasarkan nilai serapan maksimum senyawa tersebut memiliki ikatan rangkap terkonjugasi. Spektrum IR senyawa kalkon memperlihatkan adanya serapan pada bilangan gelombang 3086 $\mathrm{cm}^{-1}$ menunjukkan adanya gugus $\mathrm{C}-\mathrm{H}$ aromatik. Serapan pada bilangan gelombang $3193 \mathrm{~cm}^{-1}$ menunjukkan adanya gugus O-H. Serapan pada bilangan gelombang $2907 \mathrm{~cm}^{-1}$ menunjukkan adanya gugus $\mathrm{C}-\mathrm{H}$ alifatik. Gugus $\mathrm{C}=\mathrm{O}$ terdapat pada serapan bilangan gelombang $1648 \mathrm{~cm}^{-1}$. Gugus $\mathrm{C}=\mathrm{C}$ aromatik diperlihatkan pada serapan bilangan gelombang $1517 \mathrm{~cm}^{-1}$. Sedangkan gugus C-O diperlihatkan pada serapan bilangan gelombang $1034 \mathrm{~cm}^{-1}$.

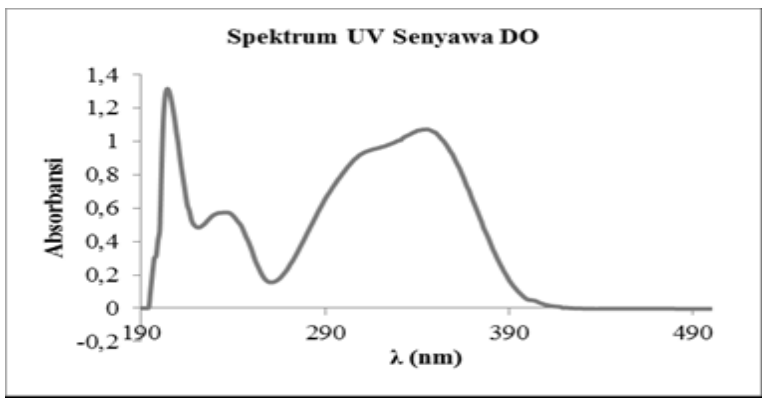

Gambar 2. Spektrum UV senyawa DO dalam pelarut metanol

Spektrum ${ }^{1} \mathrm{H}-\mathrm{NMR}$ senyawa kalkon menunjukkan bahwa jumlah proton dari senyawa tersebut sesuai dengan yang diharapkan, dapat dilihat pada Tabel 2.

Tabel 2. Interpretasi data ${ }^{1} \mathrm{H}-\mathrm{NMR}$ senyawa DO

\begin{tabular}{c|l}
\hline $\begin{array}{c}\text { Nomor } \\
\text { Atom }\end{array}$ & \multicolumn{1}{|c}{ Senyawa DO } \\
\hline & \multicolumn{1}{|c}{$\delta_{\mathrm{H}}(\mathrm{ppm})$} \\
\hline 1 & - \\
\hline 2 & - \\
\hline 3 & $6,99(\mathrm{~d}, 1 \mathrm{H})$ \\
\hline 4 & $7,43(\mathrm{dt}, 1 \mathrm{H}, J=7,5 \mathrm{~Hz})$ \\
\hline 5 & $7,03(\mathrm{t}, 1 \mathrm{H}, J=7,5 \mathrm{~Hz})$ \\
\hline 6 & $7,85(\mathrm{dd}, 1 \mathrm{H}, J \mathrm{a}=1,35 \mathrm{~Hz} ; J \mathrm{~b}=7,75$ \\
\hline $\mathrm{C} \alpha$ & $\mathrm{Hz})$ \\
\hline $\mathrm{C} \beta$ & $8,86\left(\mathrm{~d}, 1 \mathrm{H}_{\alpha}, J=15,7 \mathrm{~Hz}\right)$ \\
\hline $1^{\prime}$ & - \\
\hline $2^{\prime}$ & $8,08(\mathrm{dd}, 1 \mathrm{H}, J \mathrm{a}=1,8 \mathrm{~Hz} ; J \mathrm{~b}=8,7 \mathrm{~Hz})$ \\
\hline $3^{\prime}$ & $7,11(\mathrm{~d}, 1 \mathrm{H}, J=8,25 \mathrm{~Hz})$ \\
\hline $4^{\prime}$ & - \\
\hline $5^{\prime}$ & $7,11(\mathrm{~d}, 1 \mathrm{H}, J=8,25 \mathrm{~Hz})$ \\
\hline 6 & $8,08(\mathrm{dd}, 1 \mathrm{H}, J \mathrm{a}=1,8 \mathrm{~Hz} ; J \mathrm{~b}=8,7 \mathrm{~Hz})$ \\
\hline$-\mathrm{OCH} \mathrm{H}_{3}$ & $3,96(\mathrm{~s}, 3 \mathrm{H})$ \\
\hline
\end{tabular}


Pergeseran kimia pada $\delta 6,99 \mathrm{ppm}(\mathrm{d}, 1 \mathrm{H})$ menunjukkan proton $\mathrm{H}$ pada posisi $\mathrm{C}-3$ dengan puncak doublet. Pergeseran kimia pada $\delta 7,43$ ppm (dt, $1 \mathrm{H}, J=7,5 \mathrm{~Hz})$ menunjukkan proton $\mathrm{H}$ dengan puncak doublet of triplet pada posisi C4. Pergeseran kimia pada $\delta 7,03 \mathrm{ppm}(\mathrm{t}, 1 \mathrm{H}, J=$ $7,5 \mathrm{~Hz})$ menunjukkan proton $\mathrm{H}$ dengan puncak triplet pada posisi C-5. Pergeseran kimia pada $\delta$ $7,85(\mathrm{dd}, 1 \mathrm{H}, J \mathrm{a}=1,35 \mathrm{~Hz} ; J \mathrm{~b}=7,75 \mathrm{~Hz})$ menunjukkan proton $\mathrm{H}$ dengan puncak doublet of doublet pada posisi C-6. Pergeseran kimia pada $\delta 7,86 \mathrm{ppm}\left(\mathrm{d}, 1 \mathrm{H}_{\alpha}, J=15,7 \mathrm{~Hz}\right)$ dan $\delta 8,13$ ppm $(\mathrm{d}, 1 \mathrm{H}, J=15,75 \mathrm{~Hz})$ dengan puncak doublet berturut-turut memperlihatkan proton $\mathrm{H}$ dengan puncak doublet of doublet pada posisi C-2' dan C-6'. Pergeseran kimia $\delta 7,11 \mathrm{ppm}(\mathrm{d}, 1 \mathrm{H}, J=$ $8,25 \mathrm{~Hz})$ menunjukkan proton dengan puncak doublet pada posisi C-3' dan C-5'. Pergeseran kimia $\delta 3,96 \mathrm{ppm}(\mathrm{s}, 3 \mathrm{H})$ menunjukkan proton dengan puncak singlet untuk gugus metoksi, $\mathrm{OCH}_{3}$. Proton yang terdapat pada $\mathrm{C}_{\alpha}$ dan $\mathrm{C}_{\beta}$ memiliki nilai tetapan kopling $(J) \quad 15-16 \mathrm{~Hz}$ dengan puncak doublet. Nilai tersebut menunjukkan bahwa ikatan rangkap pada $\mathrm{C}_{\alpha}$ dan $\mathrm{C}_{\beta}$ mempunyai konfigurasi trans.

Berat molekul kalkon ditunjukkan oleh spektrum massa yang dihitung sebagai $\mathrm{C}_{16} \mathrm{H}_{15} \mathrm{O}_{3}$ $[\mathrm{M}+\mathrm{H}]^{+}$dengan puncak ion molekul $\mathrm{m} / \mathrm{z}$ 255,1021 dan massa terukur ditemukan pada $\mathrm{m} / \mathrm{z}$ 255,1024, selisih massa: 0,0003. Selisih massa senyawa kalkon sangat kecil sehingga dapat disimpulkan bahwa senyawa kalkon tersebut murni.

\section{Uji toksisitas}

Uji aktivitas toksisitas senyawa kalkon dilakukan dengan menggunakan metode Brine Shrimp Lethality Test (BSLT). Hasil uji toksisitas dari senyawa kalkon pada konsentrasi 1000, 100 dan $10 \mu \mathrm{g} / \mathrm{mL}$ terhadap larva Artemia salina yang dianalisis dengan metode analisis probit tingkat potensi toksisitas senyawa kalkon dengan nilai $\mathrm{LC}_{50}$ sebesar 49,54 $\mu \mathrm{g} / \mathrm{mL}$. Berdasarkan hasil uji aktivitas toksisitas, senyawa kalkon berpotensi sebagai senyawa antikanker karena memiliki nilai $\mathrm{LC}_{50}<200$ $\mu \mathrm{g} / \mathrm{mL}$.

\section{KESIMPULAN}

Berdasarkan hasil penelitian yang telah dilakukan, maka dpat disimpulkan bahwa senyawa kalkon diperoleh melalui reaksi kondeansasi aldol Claisen-Schmidt menggunakan katalis basa $(\mathrm{KOH})$ dibawah kondisi iradiasi gelombang mikro. Rendemen yang dihasilkan yaitu 92,07\%. Hasil karakterisasi menggunakan spektroskopi UV, IR, ${ }^{1} \mathrm{H}-\mathrm{NMR}$ dan MS menunjukkan bahwa senyawa yang diperoleh dari hasil penelitian adalah murni dan merupakan senyawa kalkon dengan struktur yang diharapkan. Senyawa kalkon memiliki toksisitas dengan nilai $\mathrm{LC}_{50}$ sebesar 49,54 $\mu \mathrm{g} / \mathrm{mL}$, hasil tersebut menunjukkan bahwa senyawa kalkon berpotensi sebagai senyawa antikanker. Namun penelitian lebih lanjut diperlukan pada penggunaan katalis lain yang hanya membutuhkan konsentrasi rendah dan volume yang sedikit

\section{DAFTAR PUSTAKA}

Ahmed, R.M., Sastry, G.V., Bano, N., Ravichandra, S., dan Raghavendra, M. 2011. Synthesis and Cytotoxic, Antioxidant Activities of New Chalcone Derivatives. Rasayan Journal Chem. 4(2): 289-294.

Chen, Y.H., Wang, W.H., Wang, Y.H., Lin, Z.Y., Wen, C.C., dan Chern, C.Y. 2013. Evaluation of the AntiInflammatory Effect of Chalcone and Chalcone Analogues in a Zebrafish Model. Molecules. 18: 2052-2560.

Desmiarti, Z. 2012. Sintesis dan Uji Toksisitas Senyawa Kalkon Turunan 4-Metoksi Asetofenon. Skripsi. Universitas Riau, Pekanbaru.

Hastiningrum, W.P., Eryanti, Y., Zamri, A. 2013. Sintesis Senyawa Kalkon Analog 3,4-Dimetoksi Asetofenon Dan Uji Toksisitas Menggunakan Metode Brine Shrimp Lethality Test (BSLT). Skripsi. Universitas Riau, Pekanbaru.

Kamble, V.M., Hatnapure, G.D., Keche, A.P., Biradjar, S., Patil, S.G., Tale, R.H., Rodge, A.H., Turkar, S.S. dan Gour, K. 2011. Synthesis and Biological 
Evaluation of a Novel Series of Methoxylatedchalcone As Antioxidant and Anti-microbial Agents. Journal of Chemical and Pharmaceutical Research. 3(6): 639-648.

Meyer, B.N., Ferrigni, N.R., Putman, J.E., Jacobsen, L.B., Nichols, D.E dan McLaughiin, J.L. 1982. Brine Shrimp: A Convencient General Bioassay for Active Plants Consistuent. Journal of Plant Medical. 45: 31-34.

Prayitno, E. 2015. Sintesis dan Uji Toksisitas

Tiga Analog Kalkon Tersubstitusi Metoksi. JOM FMIPA. 2(1).
Rahman, M.A. 2011. Chalcone: A Valuable Insight into the Recent Advances and Potential Pharmacological Activities. Chemical Sciences Journal. 1-16.

Ritriani. 2011. Sintesis Senyawa Calkon Turunan Metoksi Benzaldehid Dan Uji Aktivitas Sitotoksik Dengan Metoda Brine Shrimp Lethality Test (BSLT). Skripsi. Sekolah Tinggi Ilmu Farmasi Riau Yayasan Universitas Riau, Pekanbaru.

Syam, S., Abdelwahab, S.I., Al-Mamary, M.A., dan Mohan, S. 2012. Synthesis of Chalcones with Anticancer Activities. Molecules. $\quad$ 17: 6179-6195. 